\title{
Note
}

\section{Nondestructive Evaluation of Anthocyanin Concentration and Soluble Solid Content at the Vine and Blossom Ends of Green Mature Mangoes during Storage by Hyperspectral Spectroscopy}

\author{
Yoshio Makino ${ }^{1 *}$, Aiko Isami ${ }^{1}$, Takehiro Suhara ${ }^{1}$, Kenjiro Goto ${ }^{1}$, Seiichi Oshita ${ }^{1}$, Yoshinori Kawagoe ${ }^{2}$, \\ Shinichiro Kuroki ${ }^{3}$, Yohanes A. PURWANTO ${ }^{4}$, Usman AHMAd ${ }^{4}$ and SUtrisNo ${ }^{4}$ \\ ${ }^{1}$ Graduate School of Agricultural and Life Sciences, The University of Tokyo, Yayoi 1-1-1, Bunkyo-ku, Tokyo 113-8657, Japan \\ ${ }^{2}$ Nihon University, Kameino 1866, Fujisawa, Kanagawa 252-0880, Japan \\ ${ }^{3}$ Kobe University, Rokkodai-cho 1-1, Nada-ku, Kobe 657-8501, Japan \\ ${ }^{4}$ Bogor Agricultural University, Gedung Fateta Lt 2, Kampus IPB Darmaga, Bogor, Indonesia
}

Received September 25, 2013 ; Accepted September 10, 2014

Internal and external qualities of mangoes during storage were evaluated by hyperspectral spectroscopy. Green mature mangoes were harvested in Okinawa Prefecture, Japan, and stored for $14 \mathrm{~d}$ at $27^{\circ} \mathrm{C}$ [relative humidity $90 \%$ ]. Spectral reflectance $(380-1000 \mathrm{~nm})$, anthocyanin concentration, chlorophyll concentration in skin, and soluble solid content (SSC) in flesh were measured during storage. Anthocyanin concentration and SSC were nondestructively determined with correlation coefficients of 0.88 [root mean square error of cross validation (RMSECV) $2.96 \mathrm{mg} \cdot 100 \mathrm{~g}$ f.w. $^{-1}$ ] and 0.73 (RMSECV $0.98 \%$ ), respectively, using partial least squares regression (PLSR) models. The proposed nondestructive method may be effective for evaluating internal and external qualities of mangoes simultaneously.

Keywords: Mangifera indica L., pigment, postharvest, quality, statistical analysis, tropical fruit

\section{Introduction}

Mango is a major fruit worldwide, with the total production of mangoes, mangosteens, and guavas reaching 42 million tons (FAOSTAT, 2012) ${ }^{\mathrm{i}}$. In Japan, mangoes are produced mainly in the Okinawa and Miyazaki prefectures (3,300 tons in 2011), and production is increasing yearly (Statistical report by the Ministry of Agriculture, Forestry and Fisheries, 2011) ${ }^{\text {ii }}$. Kikuchi et al. (2011) reported that mangoes are graded based on the percentage of red color on the surface of the fruit; mangoes are subjectively graded with the naked eye. Jha et al. (2007) modeled color values of "Dashehari" mangoes, measured using a HunterLab colorimeter, by multiple linear regression (MLR), principal components regression (PCR), and partial least squares regression (PLSR) analyses. Anthocyanin is responsible for the red color of this fruit. (Berardini et al., 2005). However, no reports until now have described the objective evaluation of redness on the basis of anthocyanin concentration. That is, scientifically based prediction methods to evaluate skin redness as anthocyanin concentration are desired.

In contrast, there have been several studies on the nondestructive evaluation of internal qualities of intact mango fruit by near-infrared spectroscopy (NIRS). Tanabe et al. $(1995,1996)$ measured the soluble solid content (SSC) of "Irwin" mangoes. Guthrie and Walsh (1997) measured the dry matter (DM) of "Kensington" mangoes. Schmilovitch et al. (2000) determined the SSC, acidity, firmness, and storage period of "Tommy Atkins" mangoes. Hasbullah et al. (2002) predicted the internal qualities of heat-treated "Irwin" mangoes. Saranwong et al. (2004) predicted the SSC, DM, and starch concentrations of "Mahajanaka" mangoes. Subedi et al. (2007) 
and Subedi and Walsh (2011) predicted the DM and SSC of four varieties of mangoes. Kader (2002) reported that sweetness is one of the most important qualities for fruits in general. Accordingly, SSC should be considered as a criterion for fruit grading along with the red color. Thus, a nondestructive method for evaluating fruit contents should be developed. A hyperspectral camera was chosen in this study because it has been applied to the measurement of spectral reflectance/absorbance with spatial information (Sun, 2010).

In this study, an objective analysis of the surface redness of mangoes was attempted using a hyperspectral camera. The effectiveness of this method was investigated by evaluating differences in skin redness depending on the sampling point. Skin redness differs between the vine and blossom ends (Kikuchi et al., 2011). Furthermore, nondestructive prediction of SSC, one of the most important fruit qualities, was attempted with the hyperspectral camera. These contents change during storage owing to enzymatic activities (Medlicott et al., 1986; Saranwong et al., 2004). Therefore, we aimed to nondestructively monitor these contents post-harvest using the hyperspectral camera.

\section{Materials and Methods}

Samples and storage method Green mature mangoes (Mangifera indica L., cv. Irwin) were harvested on July 5, 2012 at a farmland in Yaese (Okinawa Prefecture, Japan). After harvest, the samples were transported to the laboratory within $24 \mathrm{~h}$ at ambient temperatures. This maturity level was selected because pigments and SSC changes are greater at this stage than at complete maturity during postharvest ripening (Makino et al., 2011). Samples consisting of 23 fruits were stored at constant temperature and humidity $\left(27^{\circ} \mathrm{C}, 90 \%\right.$ R.H.) for $14 \mathrm{~d}$ for subsequent experiments. Three fruits were selected at $2 \mathrm{~d}$ intervals and used for subsequent experiments. Samples with a wide range of SSC and skin color were prepared during storage.

Spectral reflectance measurement with a hyperspectral camera system The spectral reflectance of mangoes was measured at a range of $380-1000 \mathrm{~nm}$ using a hyperspectral camera system (JFE
Techno-Research Co., Tokyo, Japan) (Fig. 1, Table 1), with a wavelength resolution of $5 \mathrm{~nm}$ and a stage driving velocity of $0.41 \mathrm{~mm} \mathrm{~s}^{-1}$. (Siripatrawan et al., 2011). The light intensity reflected from the sample was converted by adjusting the intensity of the dark current to 0 and that of the white standard to 1 . A SpectrumAnalyzer $^{\circledR}$ ver. 1.8.6 (JFE Techno-Research Co.) was used for storing and processing the "hypercube data" (Sun, 2010) obtained with the hyperspectral camera system. The spectral reflectance of each sample was measured at $2 \mathrm{~d}$ intervals during storage.

Destructive and nondestructive analysis of SSC in flesh, anthocyanin and chlorophyll concentrations in skin The relationships between reflectance and anthocyanin concentration, chlorophyll concentration, and SSC were determined according to the method of Nicotra et al. (2003). The spectral reflectance of a mango was measured before and after sampling. A cuboidal piece of flesh $(15 \times 20 \times 15 \mathrm{~mm})$ was sampled from the vine and blossom ends. The mean spectral reflectance was calculated at the sampling site using the SpectrumAnalyzer ${ }^{\circledR}$.

Sampled skin was halved to measure anthocyanin and

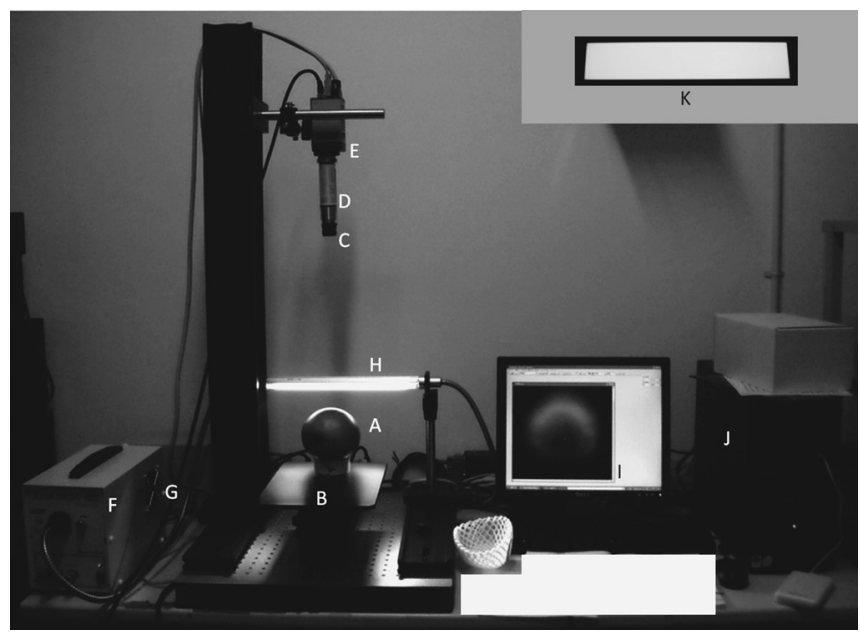

Fig. 1. Overview of hyperspectral camera system (JFE TechnoResearch, Co., Tokyo, Japan)

Table 1. Components of the hyperspectral camera system assembled by JFE Techno-Research Corporation (Tokyo, Japan)

\begin{tabular}{clll}
\hline Part & Component & Model & Maker \\
\hline A & Sample & Mango & - \\
B & Sample stage & SGSP26-200 & Sigma Koki Co., Ltd. (Tokyo, Japan) \\
C & $16 \mathrm{~mm}$ lens & C1614A & HOYA Corporation (Tokyo, Japan) \\
D & Prism/grating/prism assembly & V10C ImSpector & Spectral Imaging Ltd. (Oulu, Finland) \\
E & 12 bit CCD camera & MC1002PF & Texas Instruments Inc. (Dallas, USA) \\
F & $150 \mathrm{~W}$ Xe lamp & Super Bright 152S & SAN-EI Electric Co., Ltd. (Osaka, Japan) \\
G & $150 \mathrm{~W}$ tungsten halogen lamp & ColdSpot PCS-UHX & Nippon P•I Co., Ltd. (Tokyo, Japan) \\
H & $250 \mathrm{~mm}$ illumination rod & PDL-T-250F8 & Nippon P•I Co., Ltd. (Tokyo, Japan) \\
I & 17 inch monitor & E178FPc & Dell Co., Ltd. (Kawasaki, Japan) \\
J & Desktop computer & Dell Co., Ltd. (Kawasaki, Japan) \\
K & $40 \mathrm{~mm} \times 220$ mm white reference & Spectralon & Labsphere Inc. (North Sutton, USA) \\
\hline
\end{tabular}

${ }^{a}$ Implemented with SpectrumAnalyzer ver.1.8.6 (JFE Techno-Research Co., Tokyo, Japan) 
chlorophyll after denaturation of chlorophyllase by heating at $100^{\circ} \mathrm{C}$ for $3 \mathrm{~min}$ and homogenization. Anthocyanin concentration in the sampled skin was measured according to the method of Nagata et al. (2006). Formic acid (5\%) was used as the solvent for anthocyanin extraction. The absorbance at $530 \mathrm{~nm}$ of the extract was converted to the mass of delphinidin (molar extinction coefficient: $2.154 \times$ $10^{4} \mathrm{~L} \cdot \mathrm{mol}^{-1} \cdot \mathrm{cm}^{-1}$ ), a kind of anthocyanin. Chlorophyll $a$ and $b$ concentration was measured according to the method of Porra et al. (1989). Acetone (80\%) was used for chlorophyll extraction and absorbance was measured at 645 and $663 \mathrm{~nm}$. A nytal ${ }^{\circledR}$ nylon screen (pore size: $\varnothing 68 \mu \mathrm{m}$; Sefar AS, Heiden, Switzerland) was used for squeezing the sampled flesh. The SSC of the sampled flesh preparation was measured using a PR-201 digital refractometer (Atago Co. Ltd., Tokyo, Japan).

Prediction of anthocyanin concentration and SSC by statistical models Second derivatives of 46 reflectance spectra (Savitzky and Golay, 1964) were calculated as the independent variables. PLSR was conducted to predict SSC and anthocyanin as dependent variables using Unscrambler $^{\circledR}$ ver. 10.3 (CAMO Software AS., Oslo, Norway). The prediction models were validated by leaveone-out cross-validation. Then, the smoothing points to calculate second derivatives of spectra were selected as the number in which the root mean square error of the cross validation (RMSECV) values was minimal. The number of latent variables (LVs) selected was based on the maximal total variance of the dependent variables. Effects of storage period and the sampling site on anthocyanin concentration and SSC were estimated by two-way analysis of variance (ANOVA) and Tukey's honestly significant difference (HSD) test using JMP ${ }^{\circledR}$ Pro ver. 10.02 (SAS Inst., Cary, USA).

\section{Results and Discussion}

Changes in anthocyanin concentration and SSC at the vine and blossom ends measured by destructive methods According to the results of two-way ANOVA, differences in sampling site and storage period did not significantly affect SSC measurement. Krishnamurthy and Subramanyam (1973) reported that SSC of mangoes increased during storage due to postharvest ripening. Hasbullah et al. (2002) compared the SSC of heat-treated "Irwin" mangoes between the vine and blossom ends by NIRS and reported that SSC at the vine end was greater than that at the blossom end. The results of SSC in the present study differed from the previous reports. The variation of measured data observed in the current study was possibly caused by individual variability, given that each datum was taken from a different sample.

In contrast, differences in the sampling site significantly affected anthocyanin concentration measurement. This compound is the main pigment responsible for the red color of the skin (Barardini et al., 2005). As redness at the vine end is normally greater than that at the blossom end (Kikuchi et al., 2011), anthocyanin concentration may be affected by differences in the sampling site. However, the storage period did not affect the variability of the measured data. Medlicott et al. (1986) reported a decrease in anthocyanin during storage. The results of the current study differ from the previous report. However, these data for anthocyanin concentration and SSC can be used for calibration of spectral data for nondestructive prediction.

Prediction model for anthocyanin concentration and SSC Results of PLSR are shown in Fig. 2. According to Williams and Norris (2001), the correlation coefficients revealed that prediction models for anthocyanin and SSC were effective for screening and rough screening, respectively. In the 1990s, MLR was frequently used for predicting mango quality by NIRS (Tanabe et al., 1995, 1996; Guthrie and Walsh, 1997). More recently, PCR and PLSR have been commonly used for prediction (Schmilovitch et al., 2000; Hasbullah et al., 2002; Saranwong et al., 2004; Subedi et al., 2007; Subedi and Walsh, 2011). In previous studies, internal quality was predicted with these linear models constructed from spectral reflectance/absorbance. The correlation coefficient for SSC

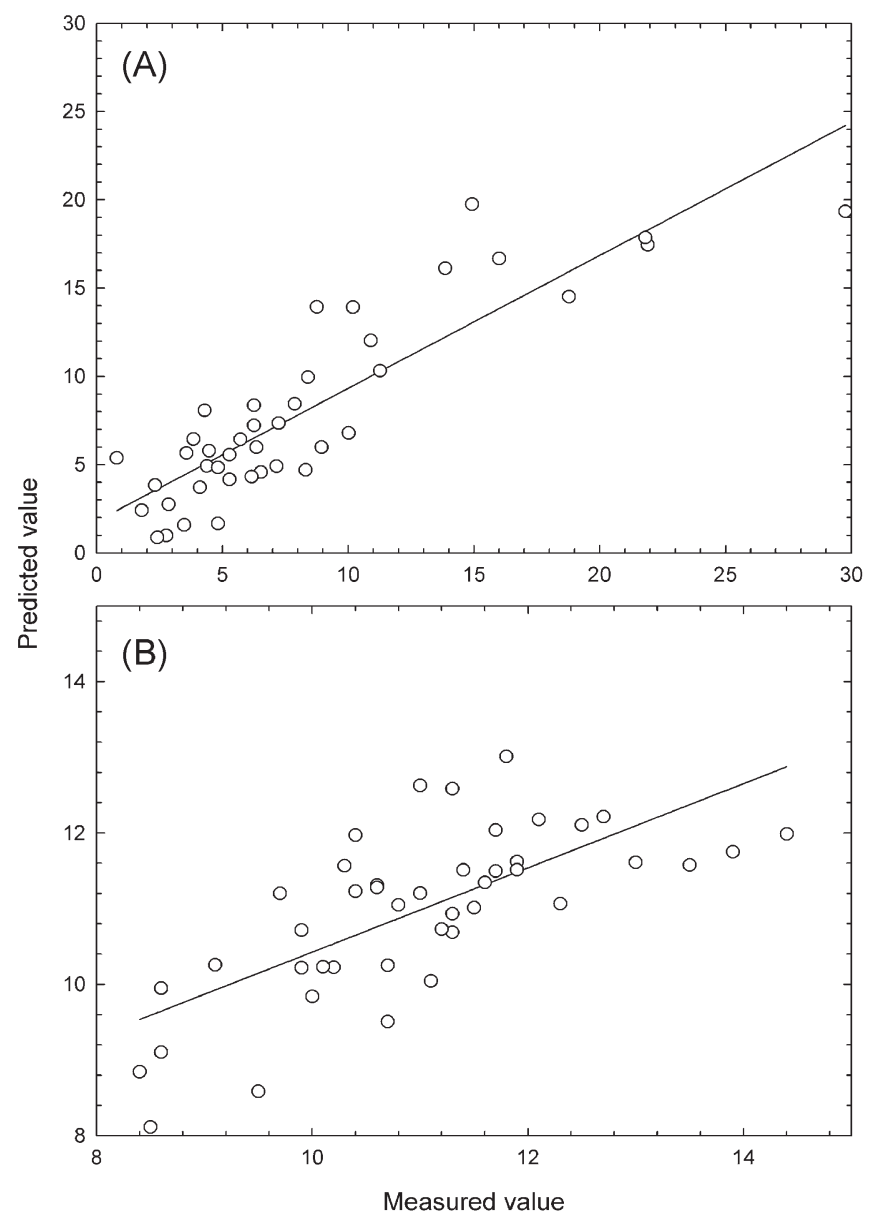

Fig. 2. Relationship between measured and predicted values of (A) anthocyanin concentration in the skin and (B) soluble solid content in the flesh of mangoes modeled by partial least squares regression analysis

The open circles denote actual values and the straight lines denote regression lines. Correlation coefficients were (A) 0.88 and (B) 0.73; root mean square errors for cross validation were (A) $2.96 \mathrm{mg} \cdot 100 \mathrm{~g}$ f.w. ${ }^{-1}$ and (B) $0.98 \%$; the numbers of latent variables were (A) 7 and (B) 3. 

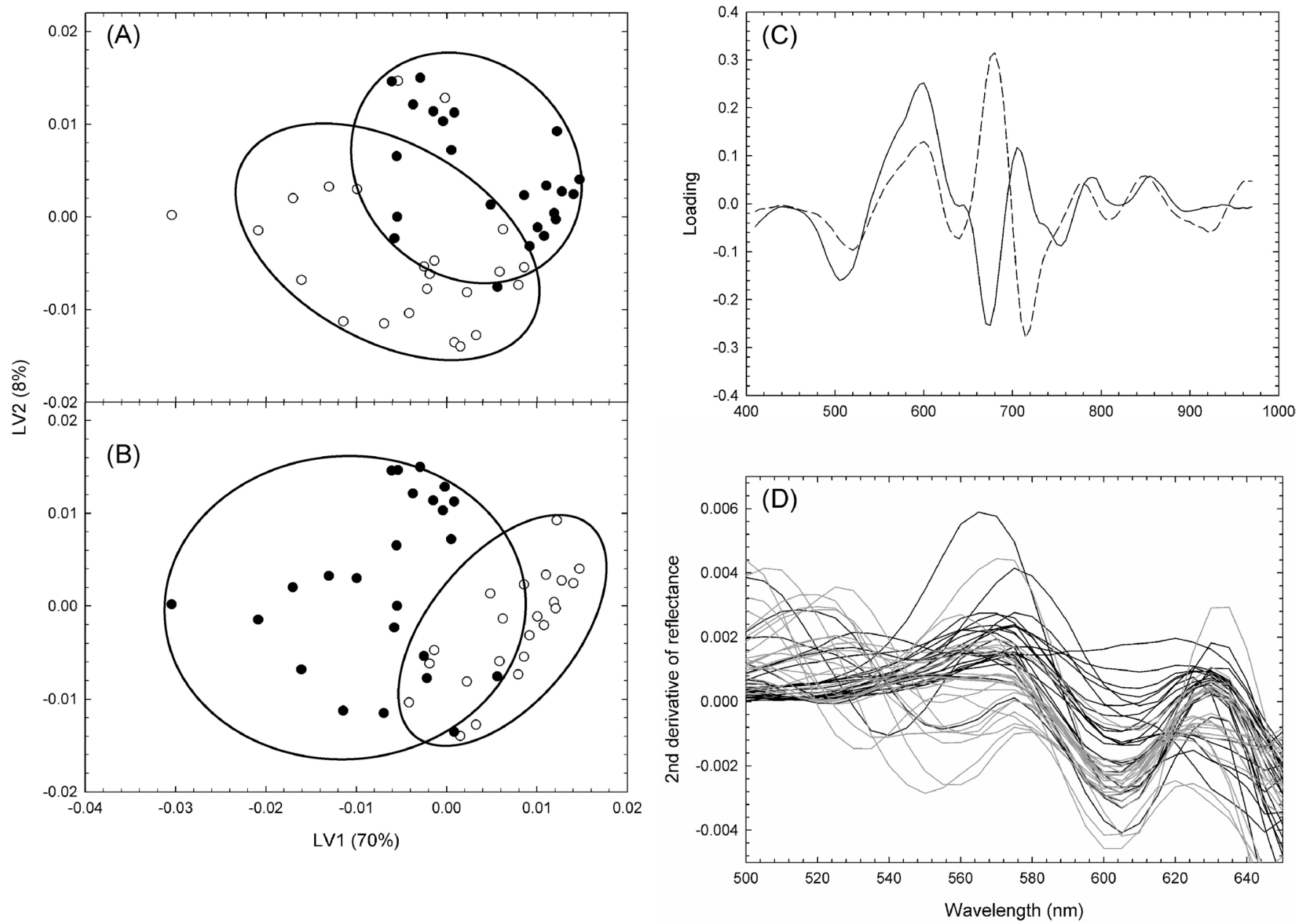

Fig. 3. Score plots of latent variables, LV 1 and LV 2 calculated by partial least squares regression analysis grouped on the basis of (A) anthocyanin concentration in the skin (threshold, $6 \mathrm{mg} \cdot 100 \mathrm{~g} \mathrm{f.w} .^{-1}$; closed circles, high; open circles, low) and of (B) chlorophyll $a$ concentration in the skin (threshold, $2.5 \mathrm{mg} \cdot 100 \mathrm{~g} \mathrm{f.w.}^{-1}$; closed circles, high; open circles, low); (C) loading plot (solid line, LV 1; dashed line, LV 2); and (D) spectral reflectance (black lines, vine end; gray lines, blossom end); the number of data points for Savitzky-Golay smoothing was 11

in the current study was lower than those in the previous studies $(0.80-0.96)$. This finding suggests that SSC prediction using hyperspectral spectroscopy is more difficult than that by point measurement. NIRS is effective for the internal prediction of SSC due to its high permeability. This indicates that this kind of electromagnetic ray significantly diffuses in the internal tissues. Therefore, it may be more difficult to evaluate differences in the concentration of internal substances between sites in a fruit than between fruits as previously reported using this kind of ray. This is the first study to report the nondestructive prediction of anthocyanin concentration in mango skin.

Score plots, loading plots and second derivatives of spectral reflectance around light absorption caused by anthocyanin are shown in Fig. 3. According to Fig. 3(A), LV 2 explained anthocyanin concentration. Nagata et al. (2006), using hyperspectral imaging, found that anthocyanin in purple-fleshed sweet potatoes absorbed visible light at around $525 \mathrm{~nm}$. In the present study, in contrast, anthocyanin in mango skin absorbed light at around $570 \mathrm{~nm}$, as shown in Fig. 3(D). When light is absorbed by a molecular species, a positive-valued peak appears as the second derivative of the spectral reflectance. Thus, loading around $570 \mathrm{~nm}$ [Fig. 3(C)] may explain the light absorption by anthocyanin. A value of the second derivative of spectral reflectance can be separated by PLSR into an LV score and a loading. As LV 2 scores increase with anthocyanin concentration, positive values of loading are considered to contribute to the light absorption observed in the second derivative of reflectance. The peak at $600 \mathrm{~nm}$ in Fig. 3(C) may not be associated with anthocyanin, judging from the result in Fig. 3(D). According to Fig. 3(B), LV 1 explained the chlorophyll $a$ concentration in the skin. Chlorophyll $a$ and $b$ in terrestrial plants (Tanaka, 2009) absorb visible light at 663 and $645 \mathrm{~nm}$, respectively (Porra et al, 1989), and the concentration of chlorophyll $a$ is much higher than that of chlorophyll $b$ (Nicotra et al., 2002). Changes in concentrations of chlorophyll $a$ and $b$ at each end over time are shown in Fig. 4. This result differed from the trends observed for anthocyanin and SSC. However, Medlicott et al. (1986) reported that chlorophyll decreases during postharvest ripening. Therefore, the trends shown in Fig. 4 agreed with the result in the previous report. According to the results of two-way ANOVA (Table 2), 

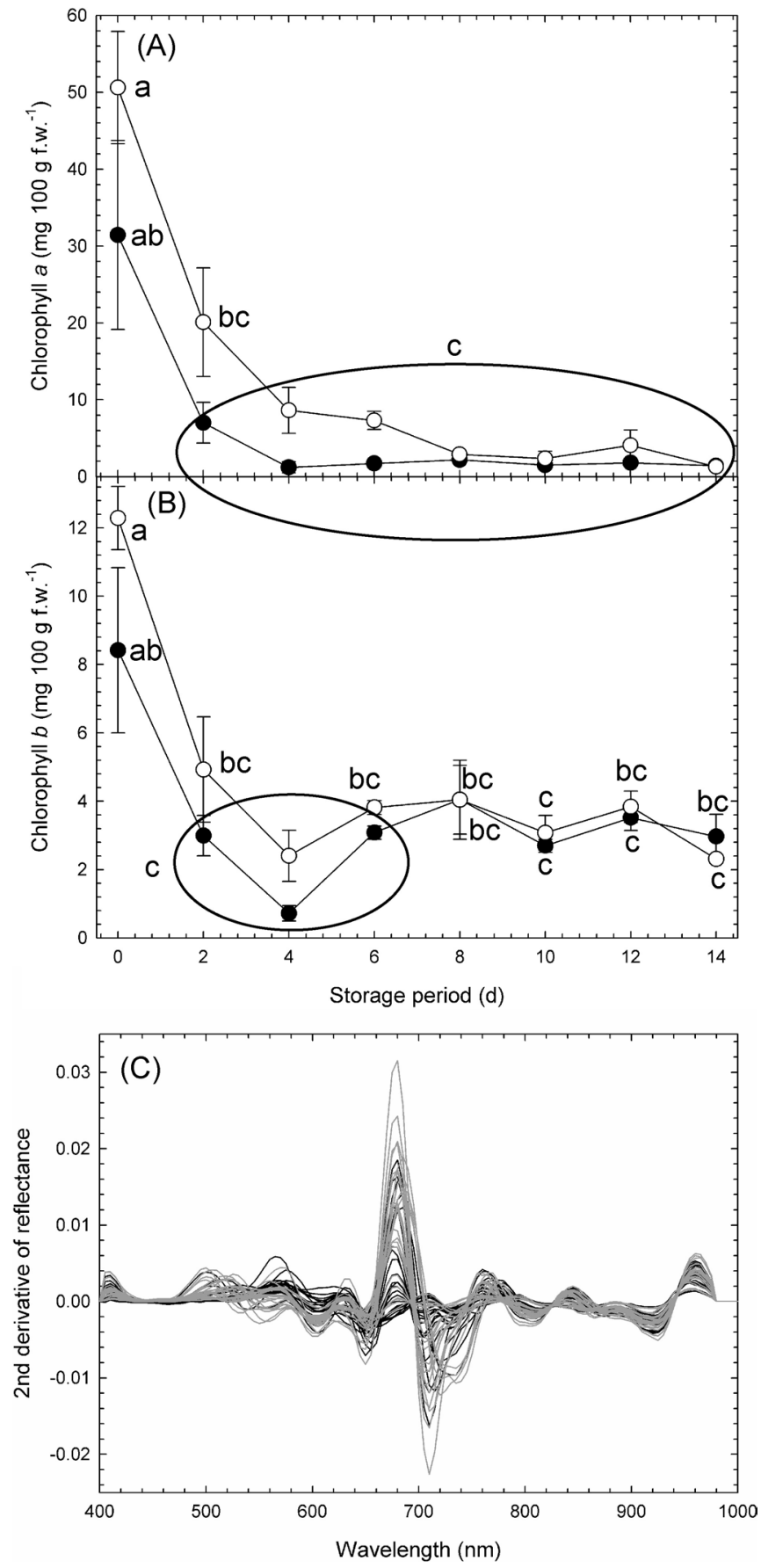

Fig. 4. Changes over time in (A) chlorophyll $a$ and (B) chlorophyll $b$ concentrations in mango skin analyzed destructively; (C) spectral reflectance (black lines, vine end; gray lines, blossom end); the number of data points for Savitzky-Golay smoothing was 11

Closed and open circles denote the means of three measured values \pm standard error at the vine and blossom ends, respectively. Within the same figure, symbols followed by the same letter are not significantly different $(\mathrm{P}<0.05$; Tukey's honestly significant difference test).

storage period and sampling site significantly affected the variance of the measured data. The concentrations of chlorophyll $a$ and $b$ at $0 \mathrm{~d}$ were significantly higher than those after $0 \mathrm{~d}$. The score of LV 1 at the blossom end was lower than that at the vine end, indicating that the negative loading for LV 1 at around $680 \mathrm{~nm}$ was influenced by chlorophyll $a$, as shown in Fig. 3(C). Thus, loading around $680 \mathrm{~nm}$ [Fig. 3(C)] may explain the light absorption by chlorophyll a. That is, LV 1 may indicate that sampling sites with high concentrations of chlorophyll $a$ contain low concentrations of anthocyanin. Understanding this relationship may contribute to the accuracy of the prediction model for anthocyanin concentration.

Score plots, loading plots and second derivatives of spectral reflectance around light absorption caused by free sugar are shown in Fig. 5. According to the score plot, LV 2 explained SSC [Fig. 5(A)]. Tanabe et al. (1995) confirmed that sucrose, fructose and glucose absorbed visible light at 750, 840, and $850 \mathrm{~nm}$, respectively, using pure chemical solutions. However, light around 745 and $835 \mathrm{~nm}$ may be influenced by free sugars, as shown in Fig. 5(D). Accordingly, the loading at 755 and $835 \mathrm{~nm}$ [Fig. 5(C)] may correspond to light absorption by free sugars. As shown in Fig. 5(B), LV 1 may indicate the concentration of chlorophyll $a$ in a similar manner to anthocyanin concentration. In Fig. 5(C), the loading at the wavelength absorbed by chlorophyll $a$ shows a large negative value. LV 1 may indicate that a sample with a high concentration of chlorophyll $a$ contains a low concentration of SSC. During postharvest ripening, SSC increases (Krishnamurthy and Subramanyam, 1973) and chlorophyll decreases (Medlicott et al., 1986) over time, suggesting that changes in SSC may be associated with changes in chlorophyll concentration.

In the present study, we described a method to nondestructively predict anthocyanin concentration in the skin and SSC in the flesh using a hyperspectral camera combined with PLSR. Evaluation of anthocyanin distribution affects the grading of fruits, and in turn the market price. When threshold values have been determined for grading, based on the distribution of anthocyanin in fruit, the proposed method may be applied to the market grading of mangoes by determining the number of pixels, which reflects skin anthocyanin content, that exceed the threshold values.

Chlorophyll $a$ concentration contributed to the accuracy of the prediction model. This observation suggests that the models we have proposed are valid for evaluating mangoes including chlorophyll $a$ harvested at the green mature stage. Models applicable to fully mature fruits using a hyperspectral camera should be considered in future.

\section{Conclusions}

Hyperspectral camera measurements in combination with PLSR were used for nondestructively measuring anthocyanin concentration in the skin and SSC in the flesh of green mature "Irwin" mangoes during storage and showed the correlation coefficients of 0.88 (RMSECV $2.96 \mathrm{mg} \cdot 100 \mathrm{~g} \mathrm{f.w.}^{-1}$ ) and 0.73 (RMSECV 0.98\%), respectively.

Acknowledgements We thank Mr. R. Teruya (Okinawa Prefectural Agricultural Research Center, Japan) for supporting to provide us with the mangoes. Financial support was provided to our research group by the Japan Society for the Promotion of Science as a Bilateral Program (Joint Research Project) from 2010 to 2012. 
Table 2. Two-way analysis of variance of the effect of storage period and sampling site of mangoes on chlorophyll $a$ and $b$ concentrations in skin measured by destructive analysis

\begin{tabular}{clcccc}
\hline Content & \multicolumn{1}{c}{ Effect } & Degree of freedom & Sum of square & F & p \\
\hline \multirow{2}{*}{ Chlorophyll $a$} & Storage period & 7 & 7490 & 19.3 & $<0.0001^{* * *}$ \\
& Sampled site & 1 & 424 & 7.64 & $0.0097^{* *}$ \\
& Interaction & 7 & 477 & 1.23 & 0.318 \\
& Error & 30 & 1660 & & \\
Chlorophyll $b b$ & Total & 45 & 10100 & & \\
& Storage period & 7 & 294 & 16.4 & $<0.0001^{* * *}$ \\
& Sampled site & 1 & 11.7 & 4.57 & $0.0411^{*}$ \\
& Interaction & 7 & 19.5 & 1.09 & 0.397 \\
& Error & 30 & 74.2 & & \\
& Total & 45 & 402 & & \\
\hline
\end{tabular}

Significant at $* 95, * * 99$ and $* * * 99.9 \%$ levels, respectively.
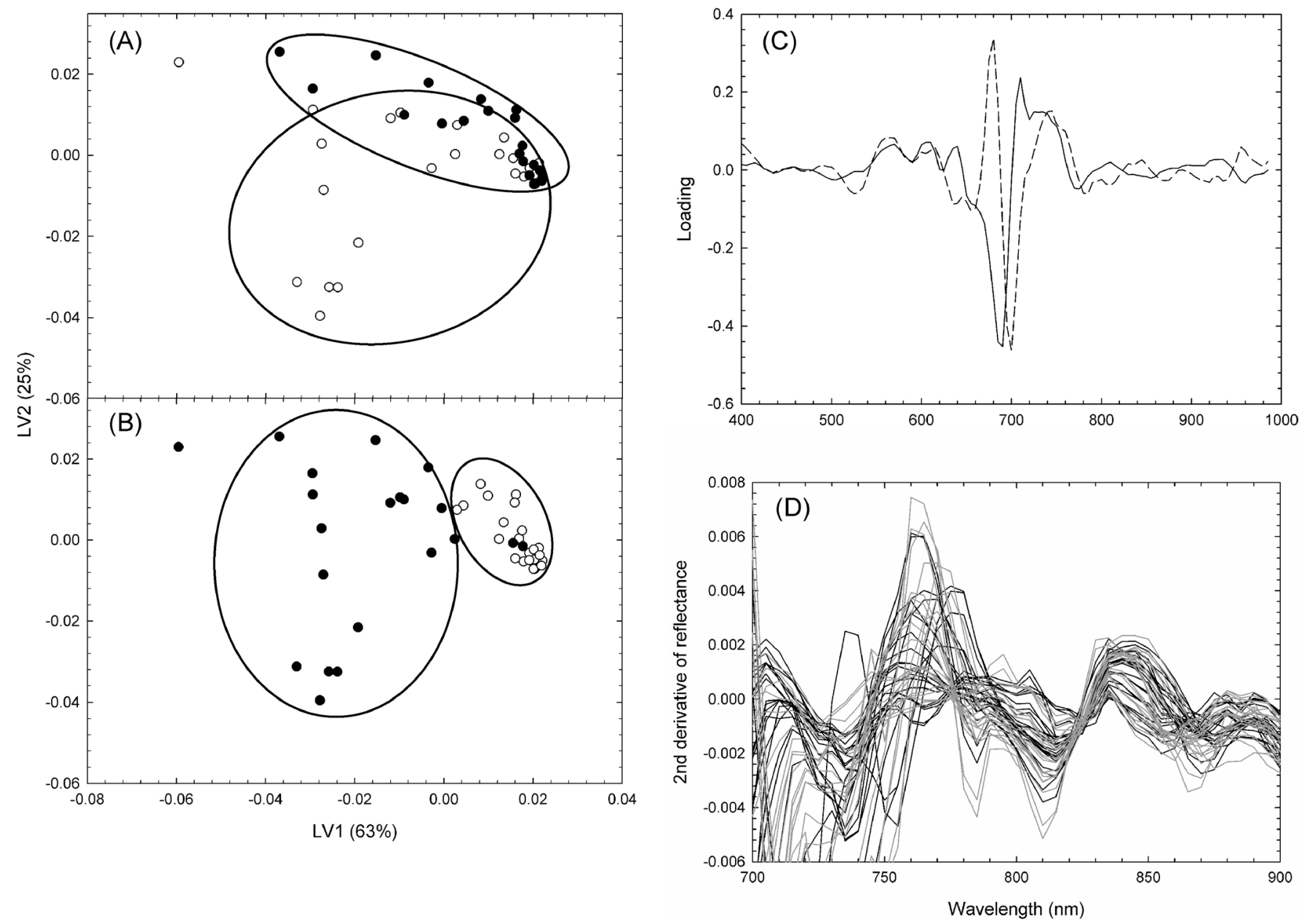

Fig. 5. Score plots of (A) LV 1 and LV 2 calculated by partial least squares regression analysis grouped on the basis of SSC in the flesh (threshold, $11 \%$; closed circles, high; open circles, low) and (B) chlorophyll $a$ concentration in the skin (threshold, $2.5 \mathrm{mg} \cdot 100 \mathrm{~g}$ f.w. ${ }^{-1}$; closed circles, high; open circles, low); (C) loading plot (solid line, LV 1; dashed line, LV 2); and (D) spectral reflectance (black lines, vine end; gray lines, blossom end); the number of data points for Savitzky-Golay smoothing was 7

\section{References}

Berardini, N., Fezer, R., Conrad, J., Beifuss, U., Carle, R., and Schieber, A. (2005). Screening of mango (Mangifera indica L.) cultivars for their contents of flavonol $O$ - and xanthone $C$-glycosides, anthocyanins, and pectin. J. Agr. Food Chem., 53, 1563-1570.

Guthrie, J. and Walsh, K.B. (1997). Non-invasive assessment of pineapple and mango fruit quality using near infrared spectroscopy. Aust. J. Exp. Agr., 37, 253-263.

Hasbullah, R., Tanabe, T., Tanaka, M., and Akinaga, T. (2002). Nondestructive prediction of internal quality of heat-treated 'Irwin' mango by near infrared spectroscopy. J. Soc. Agr. Structures, 33, 155-166.

Jha, S.N., Chopra, S., and Kingsly, A.R.P. (2007). Modeling of color values 
for nondestructive evaluation of maturity of mango. J. Food Eng., 78, 22-26.

Kader, A.A. (2002). "Postharvest Technology of Horticultural Crops." University of California Agriculture and Natural Resources Publication, Oakland.

Kikuchi, K., Nakamura, T., and Taira, E. (2011). "Problems and Prospects Associated with the Mango Producing District in Okinawa - Towards Tropical Fruit Tree Branding.” Agr. Forest. Stat. Pub. Inc., Tokyo.

Krishnamurthy S. and Subramanyam, H. (1973). Pre- and post-harvest physiology of the mango fruits: a review. Trop. Sci., 15, 167-193.

Makino Y., Isami A., Kawagoe Y., Oshita S., Kuroki S., Purwanto A. Y., Ahmad U., Sutrisno, Yasukawa N., Ishiyama R., Tsukada M., and Serizawa M. (2011). Hyperspectral image analysis of mango fruits during storage. Presented at $241 \mathrm{st}$ Am. Chem. Soc. Nat. Meeting, Anaheim, Mar. 29, pap. no. AGFD67.

Medlicott, A.P., Bhogal, M., and Reynolds, S.B. (1986). Change in peel pigmentation during ripening of mango fruit (Mangifera indica var. Tommy Atkins). Ann. Appl. Biol., 109, 651-656.

Nagata, M., Kobayashi, T., Tallada, J., Toyoda, H., and Goto, Y. (2006). Study on anthocyanin pigment distribution estimation for fresh fruits and vegetables using hyperspectral imaging. J. Soc. High Tech. Agr., 18, $42-$ 49.

Nicotra, A.B., Hofmann, M., Siebke, K., and Ball, M.C. (2003). Spatial patterning of pigmentation in evergreen leaves in response to freezing stress. Plant Cell Environ., 26, 1893-1904.

Porra, R.J., Thompson, W.A., and Kriedemann, P.E. (1989). Determination of accurate extinction coefficients and simultaneous equations for assaying chlorophylls $a$ and $b$ extracted with four different solvents; verification of the concentration of chlorophyll standards by atomic absorption spectroscopy. Biochimica Biophysica Acta , 975, 384-394.

Saranwong, S., Sornsrivichai, J., and Kawano, S. (2004). Prediction of ripestage eating quality of mango fruit from its harvest quality measured nondestructively by near infrared spectroscopy. Postharvest Biol. Technol., 31, 137-145.
Savitzky, A. and Golay, M.J.E. (1964). Smoothing and differentiation of data by simplified least squares procedures. Anal. Chem., 36, 1627-1639.

Schmilovitch, Z., Mizrach, A., Hoffman, A., Egozi, H., and Fuchs, Y. (2000). Determination of mango physiological indices by near-infrared spectrometry. Postharvest Biol. Technol., 19, 245-252.

Siripatrawan, U., Makino Y., Kawagoe Y., and Oshita S. (2011). Rapid detection of Escherichia coli contamination in packaged fresh spinach using hyperspectral imaging. Talanta, 85, 276-281.

Subedi, P.P. and Walsh, K.B. (2011). Assessment of sugar and starch in intact banana and mango fruit by SWNIR spectroscopy. Postharvest Biol. Technol., 62, 238-245.

Subedi, P.P., Walsh, K.B., and Owens, G. (2007). Prediction of mango eating quality at harvest using short-wave near infrared spectroscopy. Postharvest Biol. Technol., 43, 326-334.

Sun, D.W. (2010). "Hyperspectral Imaging for Food Quality Analysis and Control." Academic Press, Waltham.

Tanabe, T., Akinaga, T., Kohda, Y., Kawasaki, S., Kouno, Y., Maeda, H., Mizuno T., and Aoki, H. (1996). Internal quality measurement of tropical fruits by near infrared spectroscopic technique (Part 2) - Using the specific NIR absorption wavelength on water, cellulose and sugar -. $J$. Soc. Agr. Structures, 27, 29-34.

Tanabe, T., Akinaga, T., Kohda, Y., Kouno, Y., Maeda, H., and Mizuno T. (1995). Internal quality measurement of tropical fruits by near infrared spectroscopic technique. J. Soc. Agr. Structures, 26, 17-24.

Tanaka, R. (2009). Analysis of chlorophyll and its metabolic intermediates. Low Temp. Sci., 67, 215-325.

Williams, P. and Norris K. (2001). "Near-infrared Technology 2nd ed." Am. Assoc. Cereal Chem., Inc., St Paul.

\section{URL Cited}

i) http://faostat.fao.org/home/ (Mar.6, 2014)

ii)http://www.e-stat.go.jp/SG1/estat/List.do?lid=000001115710 (Mar.6, 2014) 